\title{
Hydroxypropylation of Guar Splits: Kinetics and
}

\section{Rheology}

Jie Gao and Brian P. Grady*

School of Chemical, Biological and Materials Engineering, University of Oklahoma, Norman, OK 73019 


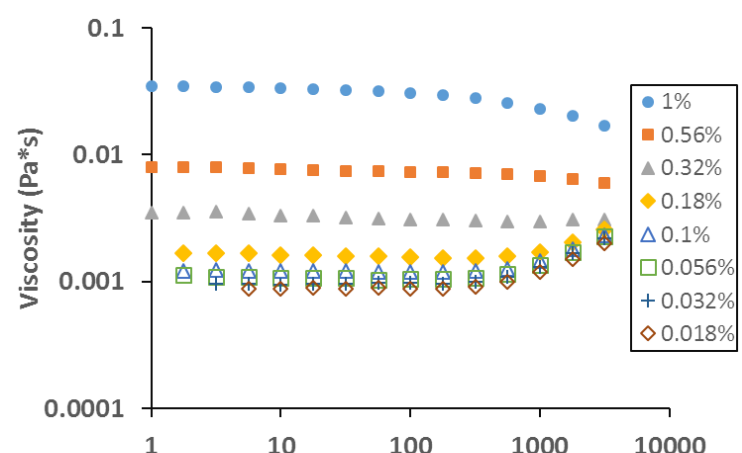

(A)

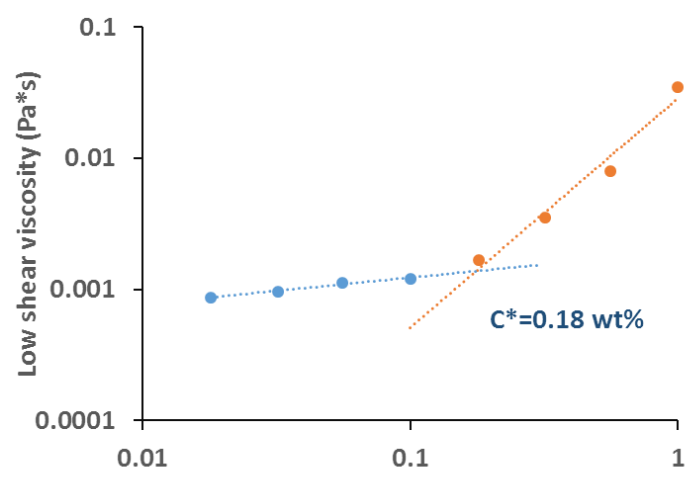

(B)

Concentration (wt \%)

Figure S1. (A) Viscosity vs shear rate curves for different HPG (MS =0.74) concentrations. (B) Zero shear viscosities at different HPG concentrations.

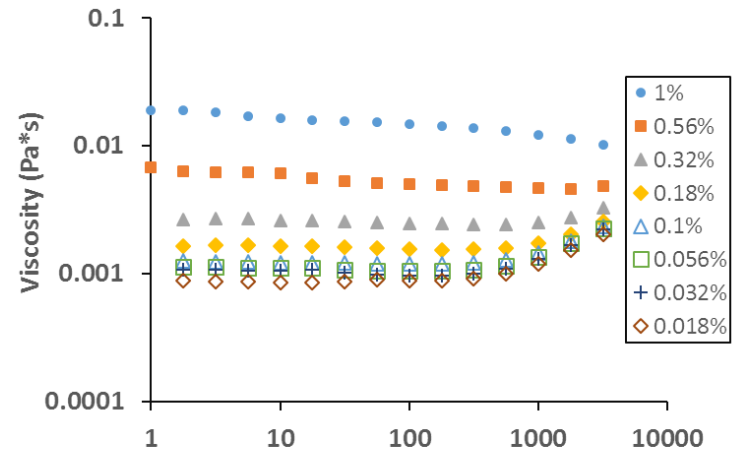

(A)

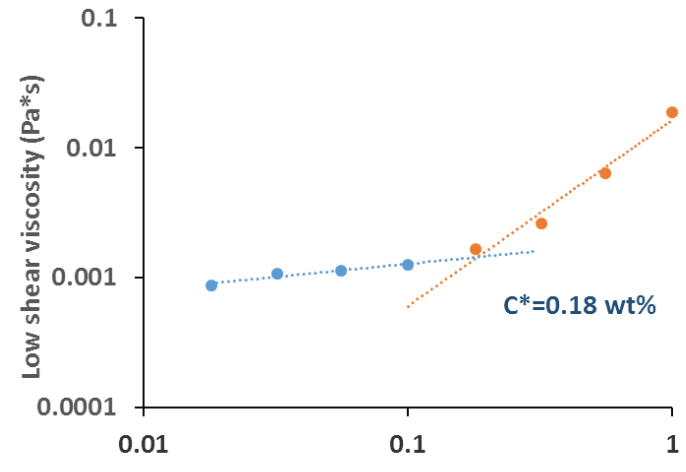

(B)

Concentration (wt \%)

Figure S2. (A) Viscosity vs shear rate curves for different HPG (MS =0.94) concentrations. (B) Zero shear viscosities at different HPG concentrations.

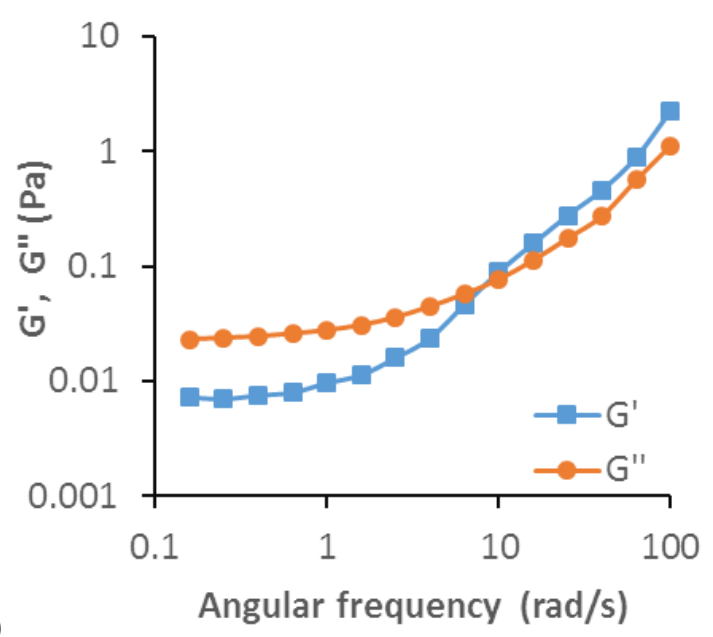

(A)

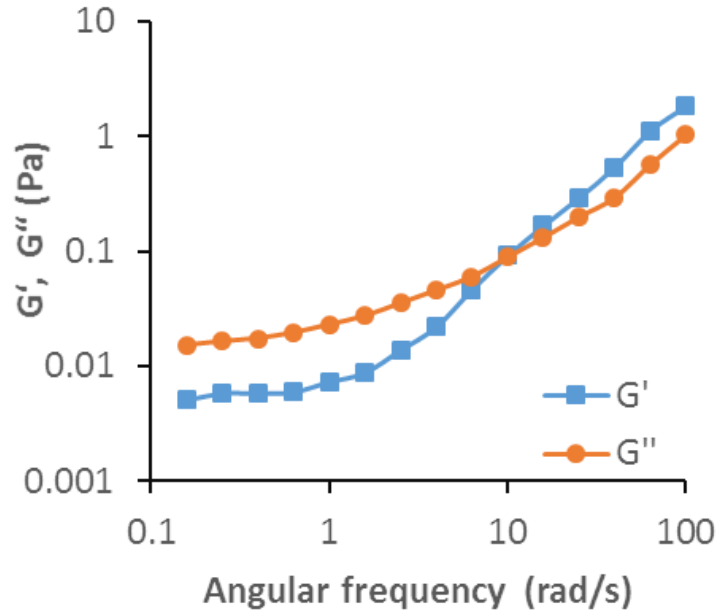

(B)

Figure S3. Storage and loss moduli (at $25^{\circ} \mathrm{C}$ ) of (A) $0.5 \%$ uncrosslinked HPG solution, and HPG solution with (B) 200 ppm borate cross-linker. 